\title{
Accelerated treatment of postpneumonectomy empyema - report of 12-year experience
}

\author{
J. WOJCIK ${ }^{1, *}$, T. GRODZKI ${ }^{1}$, B. KUBISA ${ }^{1}$, J. PIEROG ${ }^{1}$, K. SAFRANOW $^{2}$, G. NAPRAWA ${ }^{3}$ \\ ${ }^{1}$ Thoracic Surgery Department, Pomeranian Medical University, Szczecin, Poland; ${ }^{2}$ Department of Biochemistry and Medical Chemistry, \\ Pomeranian Medical University Szczecin, Poland; ${ }^{3}$ General Medicine Department, Regional Hospital Zdunowo, Szczecin, Poland
}

${ }^{*}$ Correspondence: grodzki@grodzki.szczecin.pl

Received May 25, 2012/ Accepted September 19, 2012

\begin{abstract}
We report 12-year experience in the accelerated treatment (AT) of postpneumonectomy empyema (PPE). There were 38 patients ( 7 females, 31 males) in age 19-80 years. 34 patients underwent pneumonectomy due to non-small cell lung cancer (NSCLC), 2 for other malignancies, and 2 for lung abscess. 19 right and 19 left pneumonectomies were performed. PPE was caused by bronchopleural fistula in 16 cases (42.1\%) and by pleural infection in 22 patients (57.9\%). The interval between first symptoms of PPE and AT ranged 1-47 months. The technique described by Schneiter et al. is based on repeated debridement/lavage of the postpneumonectomy cavity every second day performed a total of three times. 35 patients ( $92.1 \%)$ were free from empyema definitively. 4 of them required additional thoracomyoplasty and another 2 of them thoracostomy due to PPE recurrence. 1 patient (2,6\%) died during hospitalisation and $2(5.2 \%)$ didn't complete treatment and remained drain carriers. AT alone without additional procedures healed 29 patients (76.3\%). Follow up time for the NSCLC group was 8-148 months (median 67). Cancer recurrence or second malignancy rate was 8/36 (22\%). Accelerated treatment of PPE is safe and effective. It provides cure for the vast majority of patients without thoracoplasty. Patients with cancer and PPE tend to live longer than similar patients without PPE.
\end{abstract}

Key words: postpneumonectomy empyema, accelerated treatment, lung cancer

The incidence of postpneumonectomy empyema $[\mathrm{PPE}]$ is $5-10 \%$. Bronchopleural fistula[BPF], infection of the pleural cavity without BPF, and wound infection with external fistula $[\mathrm{EF}]$ are the main factors leading to PPE development. Immediate surgical intervention is useful in early (up to 48 hours) bronchial stump insufficiency [BSI] only. Chest tube drainage is the most frequent mode of treatment for the acute phase of PPE. The chronic phase of PPE (including BPF) usually requires complicated and time-consuming treatment [1-6]. Since 1998, accelerated treatment [AT] has been applied in the Thoracic Surgery Department in Szczecin. AT allows to cure of PPE in the majority of patients within 14 days of hospitalization without thoracoplasty, thoracomyoplasty, or open window thoracostomy with a low level of morbidity [7-9]. This paper presents our 12-year experience with this method.

\section{Patients and methods}

The idea of AT was invented in 1995 in Zurich, Switzerland based on a technique described by Deschamps [3]. Our depart- ment is the second one to apply this method widely. The first Swiss data were published in 2001 and results of treatment of 75 patients from both centers (Zurich and Szczecin) were described in 2008 [1, 7, 10]. Our initial results (15 cases) were published in 2001 and $2002[8,9]$. This paper presents much larger group (38 cases) and is focused on long term results. This is the modification of the routine methods used for years in thoracic surgery and was approved by our hospital ethics committee. All patients were fully informed about the technique and signed the formal informed consent. AT is usually based on pleural debridement and lavage performed every second day under general anesthesia, repeated three times. Bronchial fistula is closed during the first intervention. All procedures are based on curettage of the pyogenic pleural membrane (using a sharp spoon and sponges) followed by intensive lavage with diluted povidone-iodine solution (dilution 1:10). Special attention is needed during mediastinum debridement because of vital hilar structures in this region. The pleural cavity is packed with povidone-iodine soaked towels (solution 1:10 with saline) at the end of first two interventions 
and thoracotomy is temporarily closed. The number of inserted towels depends on pleural cavity size and ranged from 2-20. This maneuver must be performed carefully to avoid excessive mediastinal compression. However, there is usually more space for 1-3 towels on the second intervention versus the first one. Three interventions were required to obtain clean and red granulation tissue on the pleural wall in the majority of the group. This good healing status allowed for filling of the pleural cavity with antibiotic solution and definitive closure of the thoracic approach (Fig.1,2). A fourth step of surgery was applied in only six cases. Patients were fed and fully mobilized between surgical interventions. The basic solution of antibiotics was modified in accordance with microbiological findings as previously described $[1,7]$. The contraindications for this type of surgery are the same as for major thoracic procedures (poor physical status, active sepsis, severe circulatory and/or respiratory insufficiency, renal failure, active malignancy etc). If the BPF cannot be closed during first stage of the procedure, it is contraindicated to continue and one should consider another type of treatment. The complication rate is usually lower than of similar major thoracic procedures and most frequently include atrial fibrillation, secondary wound healing and lack of chest wall fluid-tightness.

The group of 38 patients underwent AT and completion of treatment in 1998-2010. Thirty-six patients were pneumonectomized for malignancy diagnosis and two for non-malignant conditions. The bronchial stump was closed by running Klinkenberg non-absorbable sutures in 30 cases and stapled in 8 cases. All bronchial stumps were covered by pedicled pericardial fat flap or the azygos vein during primary pneumonectomy. All pneumonectomies performed for oncologic reasons were followed by radical mediastinal lymphadenectomy. Nine patients underwent neoadjuvant chemotherapy; four of these developed postpneumonectomy BPF. Ten patients underwent adjuvant radiotherapy and one patient received adjuvant chemotherapy. One BPF was diagnosed 51 months after pneumonectomy followed by adjuvant radiotherapy and chemotherapy. During the acute phase of PPE (all with BPF) chest tube drainage was applied in 26 cases when the re-operation was contraindicated due to severe condition of the patients. Seven patients underwent thoracocentesis and both methods were performed in five additional patients. Thirteen pinhole fistulae $(1-3 \mathrm{~mm}$ of diameter) were healed before AT during long drainage time (38-658 days, median 157). Such a prolonged drainage time was usually caused by initial refusal of the patients for more aggressive treatment. Twenty percent argentum nitrate [AN] was locally applied during 3-5 bronchoscopies in 11 patients. For an additional two patients, fibrin glue deposits were successfully applied into the fistula lumen. Large fistulae ( $>3 \mathrm{~mm}$ of diameter) were closed during the first step of AT using a myoplastic technique in three cases. Median duration

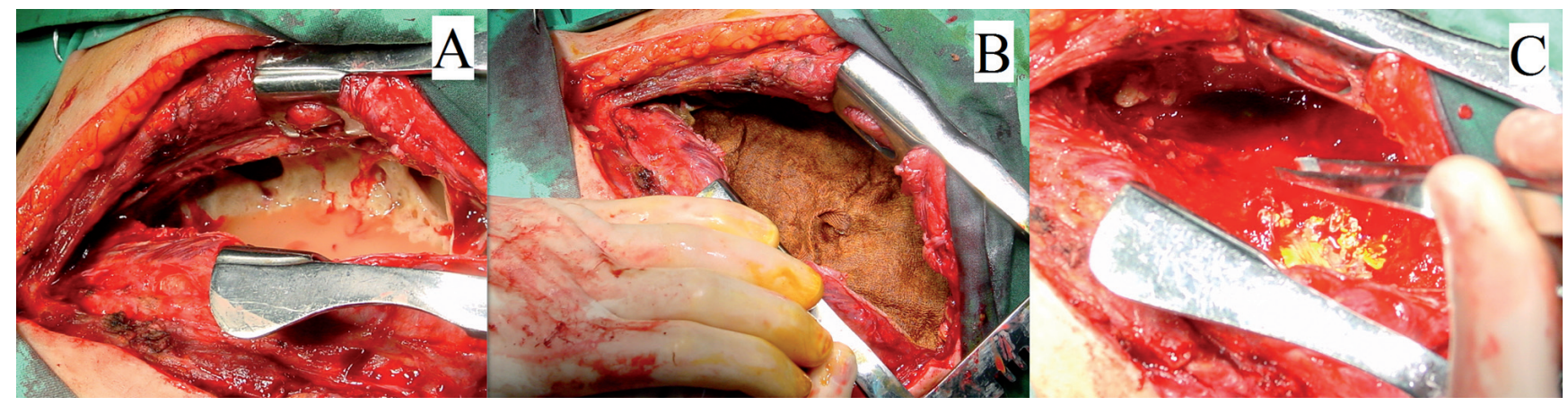

Figure 1. (A) Pleural cavity during first intervention before curettage (pleural debridement). (B) Pleural cavity after debridement and filled povidoneiodine soaked towels. (C) Pleural cavity during second intervention with improvement of local state.

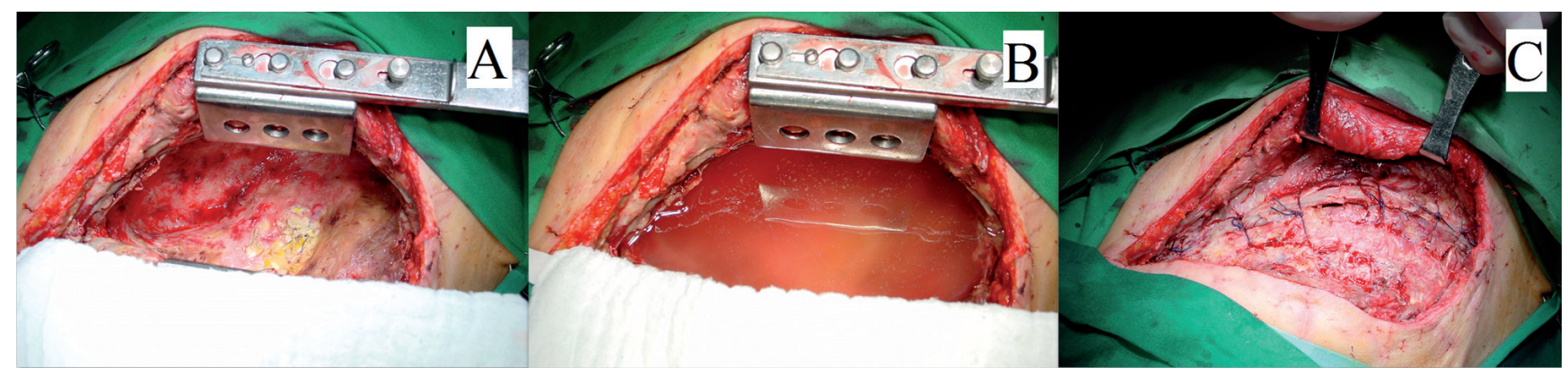

Figure 2. (A) Pleural cavity after final debridement/lavage with clean granular tissue. (B) Pleural cavity filled by antibiotics solution before closure the approach. (C) Ribs-suture during last intervention. The main goal after final intervention is maintenance tightness of the approach. 
of preoperative medical treatment of PPE was seven months. All patients were qualified for AT during the chronic phase of PPE; patients were in good health without any symptoms of active malignant disease. Tables 1 and 2 report patient characteristics. Kaplan-Maier survival curve, log-rank test, and Cox bivariate model were used for statistics.

\section{Results}

Successful treatment of PPE was achieved in $92.1 \%$ (35/38 cases). One patient (2.6\%) died during the procedure due to massive pulmonary artery embolus. There were no other serious morbidities. Two patients (5.2\%) interrupted treatment and remained drain carriers. Twenty-nine patients (76.3\%) completed the series of lavages without requiring further intervention. The recurrence rate of PPE was $15.7 \%$ (6 patients) during 3-60 months follow-up after AT. There were two cases

Table. 1. Characteristics of the group. NSCLC classification-(UICC1997'edition)

\begin{tabular}{|c|c|}
\hline $\begin{array}{l}\mathrm{PPE} / \text { postpneumonectomy BPF incidence rate for all } \\
\text { pneumonectomies (\%) }\end{array}$ & $4.2 / 1.8$ \\
\hline No. of patients of the presented group & 38 \\
\hline Female/male & $7 / 31$ \\
\hline Age-median (range) & $62(19-80)$ \\
\hline Side right/left & $19 / 19$ \\
\hline $\mathrm{BPF}$ right/left & $8 / 8$ \\
\hline Preoperative closure of BPF & 13 \\
\hline $\begin{array}{l}\text { Pleural infection without bronchial fistula and wound } \\
\text { infection }\end{array}$ & 12 \\
\hline Wound infection with external fistula & 10 \\
\hline Occurrence of BPF after pneumonectomy (days) & $5-1460$ \\
\hline Duration of PPE treatment before AT (month) & $1-47$ \\
\hline NSCLC-squamous carcinoma & 24 \\
\hline NSCLC-adenocarcinoma & 6 \\
\hline NSCLC-mixed carcinoma & 2 \\
\hline NSCLC-solid carcinoma & 2 \\
\hline Carcinoid & 1 \\
\hline $\begin{array}{l}\text { Malignant mesothelioma (pleuropericardiopneumonec- } \\
\text { tomy) }\end{array}$ & 1 \\
\hline Lung abscess & 2 \\
\hline T1b (TNM classification of malignant mesothelioma) & 1 \\
\hline T2 (NSCLC) & 8 \\
\hline T3 (NSCLC) & 25 \\
\hline T4 (NSCLC) & 2 \\
\hline N0 (NSCLC) & 21 \\
\hline N1 (NSCLC) & 6 \\
\hline N2 (NSCLC) & 9 \\
\hline IB (NSCLC) & 3 \\
\hline IIB (NSCLC) & 18 \\
\hline IIIA (NSCLC) & 13 \\
\hline IIIB (NSCLC) & 2 \\
\hline
\end{tabular}

[NSCLC]-Non-small cel lung cancer, [PPE]-Postpneumonectomy empyema, [AT]-Accelerated treatment, [BPF]-Bronchopleural fistula. with recurrence of primary healed BPF and four cases of PPE without BPF. Thoracomyoplasty and open window thoracostomy with myoplasty technique were used in two cases with reopened BPF. Three patients without BPF were treated by thoracomyoplasty and one was treated by open window thoracostomy with intrathoracic fat pedicle transposition (an overweight patient). Massive viral infection was followed by recurrence of PPE without BPF 60 months after AT in one patient. Follow up time for patients with non-small cell lung cancer [NSCLC] ranged from 8-148 months with a median survival of 67 months. Cancer recurrence or second malignancy occurred in $8 / 35$ cases (22.8\%). Five of these patients were successfully treated surgically and three patients died. Nine patients died due to non-oncologic reasons. One patient was lost from observation after 56 months of follow-up because of migration. Another 20 NSCLC patients are still being followed (IB-1, IIB-12, IIIA-7). Thirty-three NSCLC patients

Table 2. Patient characteristics-part 2. [n.s.]-non significant.

\begin{tabular}{|c|c|}
\hline Positive bacteriology of the pleura before AT $=20 / 38$ & $52.6 \%$ \\
\hline Serratia species & 6 \\
\hline Pseudomonas species & 5 \\
\hline Staphylococcus species & 4 \\
\hline Streptococcus species & 3 \\
\hline Acinetobacter species & 1 \\
\hline Haemophilus species & 1 \\
\hline Success rate after first treatment (number/\%) & $29 / 76.3 \%$ \\
\hline Recurrence rate of PPE (number/\%) & $6 / 15.7 \%$ \\
\hline Recurrence of BPF (number/\%) & $2 / 12.5 \%$ \\
\hline $\begin{array}{l}\text { Complete treatment with additional fenestration } \\
\text { (recurrence) }\end{array}$ & 2 \\
\hline $\begin{array}{l}\text { Complete treatment with thoracomyoplasty } \\
\text { (recurrence) }\end{array}$ & 4 \\
\hline $\begin{array}{l}\text { Overall success rate (including second attempt) } \\
\text { (number/\%) }\end{array}$ & $35 / 92.1 \%$ \\
\hline 30-d mortality (number/\%) & $1 / 2.63 \%$ \\
\hline $\begin{array}{l}\text { Interrupted treatment (drain carrier), NSCLC-1, } \\
\text { mesothelioma-1 }\end{array}$ & 2 \\
\hline Deceased patients (number/\%) & $13 / 35.13 \%$ \\
\hline $\begin{array}{l}\text { NSCLC group in follow-up (including case of } \\
\text { carcinoid) }\end{array}$ & 20 \\
\hline 5-year survival (including the case of carcinoid) & $19 / 54 \%$ \\
\hline $\begin{array}{l}5 \text {-year survival group stage IB (mesothelioma } \\
\text { malignum) }\end{array}$ & 1 \\
\hline 5-year survival group stage IIB (NSCLC) & $12 / 18(66.6 \%)$ \\
\hline 5-year survival group stage IIIA (NSCLS) & $5 / 13(38.4 \%)$ \\
\hline 5-year survival group stage IIIB (NSCLC) & $1 / 2(50.0 \%)$ \\
\hline Type of malignancy - impact on long-term survival & $\mathrm{p}=0.19361$ (n.s.) \\
\hline $\mathrm{BPF}$ & $\mathrm{p}=0.56304$ (n.s.) \\
\hline Side of operation & $\mathrm{p}=0.86112$ (n.s.) \\
\hline TNM classification & $\mathrm{p}=0.40078$ (n.s.) \\
\hline $\mathrm{N}$ stage & $\mathrm{p}=0.90248$ (n.s.) \\
\hline Adjuvant radiotherapy & $\mathrm{p}=0.57484$ (n.s.) \\
\hline Neoadjuvant chemotherapy & $\mathrm{p}=0.66094$ (n.s.) \\
\hline
\end{tabular}


who completed the treatment were included in the statistical analysis. The 5- and 10-year survival rates were $69 \%$ and $51 \%$, respectively (Fig.3). There was a predominance of non cancer-related deaths during outpatient follow-up (75\% of all who died) (Fig.4,5). Only two patients in the study group died because of NSCLC recurrence, 14 and 16 months after pneumonectomy. One patient died due to a second neoplasm after 21 months. The median survival time (67 months) concerned all stages of NSCLC including the TNM N $\mathrm{N}_{2}$-stage patients, which consisted of nine patients (one death caused by NSCLC recurrence). One patient with metastatic lesion detected eight years after pneumonectomy was successfully treated surgically. There were two non-cancer related deaths and six patients are still being followed. All patients with stage $\mathrm{N}_{2}$ disease underwent adjuvant radiotherapy and one patient underwent adjuvant chemotherapy. Median follow-up time of this group reached 58 months and ranged between 8-105 months. Twelve stage $\mathrm{N}_{0}$ patients and two stage $\mathrm{N}_{1}$ patients remain in follow-up. Two patients from this group were successfully treated for a second neoplasm. Type of malignancy, BPF occurrence, side of operation, oncologic staging, $\mathrm{N}$ status, adjuvant radiotherapy, and neodjuvant chemotherapy were not statistically significant predictors of survival (Tab.2). There were two patients with stage T4 tumors. They were radically treated with follow-up of 8 and 85 months. Both patients died due to circulatory and respiratory insufficiency after pneumonectomy without symptoms of recurrence. Higher T stage was also an independent risk factor - $p=0.0496$. Cancer-related death risk correlated significantly with recurrence of NSCLC as well as with number of lavages greater than three $-\mathrm{p}=0.01074$ and $\mathrm{p}=0.011$, respectively. There were six patients who received four lavages each (five with malignancy and one with lung abscess). Two patients died due to recurrent NSCLC.

\section{Discussion}

Treatment of PPE has changed during last century. Furthermore, treatment varies depending upon the phase of PPE, presence or absence of BPF, general patient condition, oncologic status and experience of the surgical team [1-7, 11-14]. Today, the most popular treatment is combined open window thoracostomy with partial thoracoplasty and intrathoracic muscle transposition. Deformation of the chest cage and limitation of ipsilateral arm mobility are typical side effects $[2-4,15]$. AT is a more aggressive version of the Clagett and modified Clagett procedure based on repeated peritoneal lavage for peritonitis $[1-3,7,11,12,16]$. The main idea of AT is sterilization of the pleural cavity without opening a chest window or thoracomyoplasty with definitive closure of the thoracic approach. Additional removal of one or two ribs and even muscle transposition for closure of fistula or omentoplasty is still AT in an extended version. It is currently possible to perform this procedure via a minimally invasive approach [17]. Despite good efficiency, the use of AT is limited. The

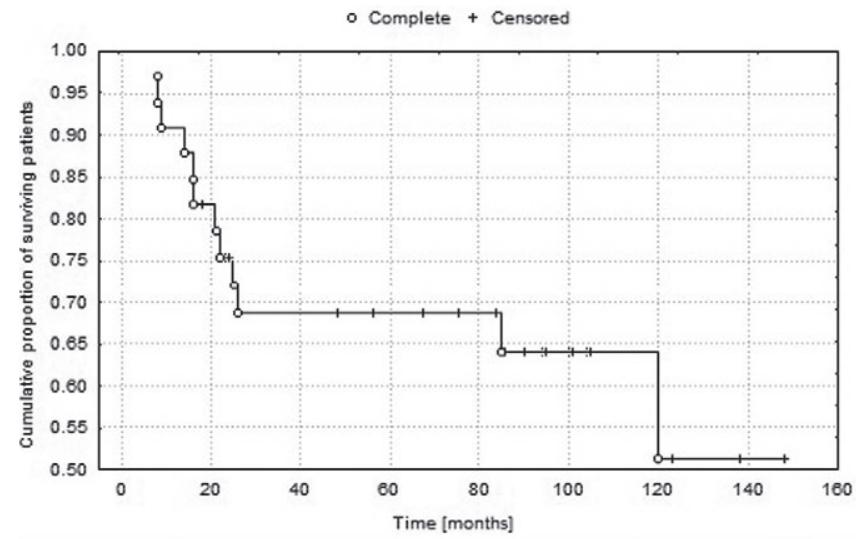

Figure 3. Cumulative proportion of surviving patients in the whole group. Five-year survival was $69 \%$ and 10 -year survival was $51 \%$.

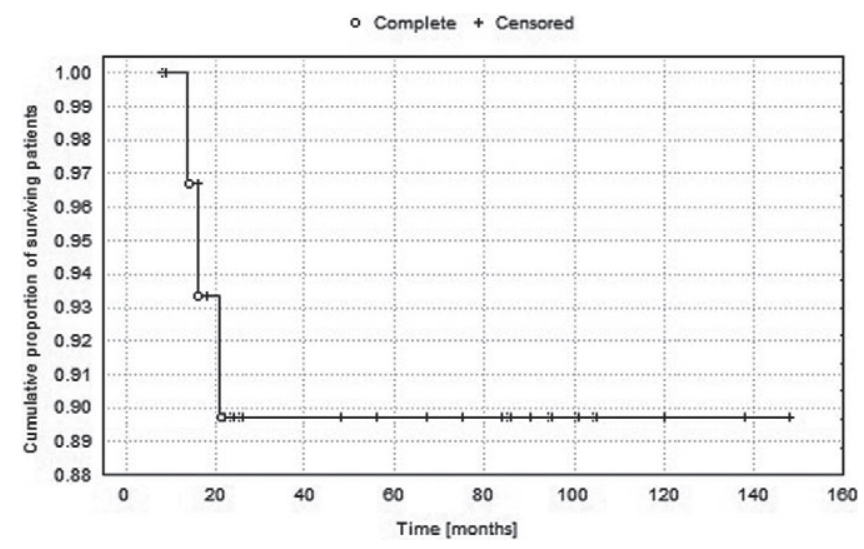

Figure 4. Kaplan-Meier plot for cancer-related deaths (3/33).

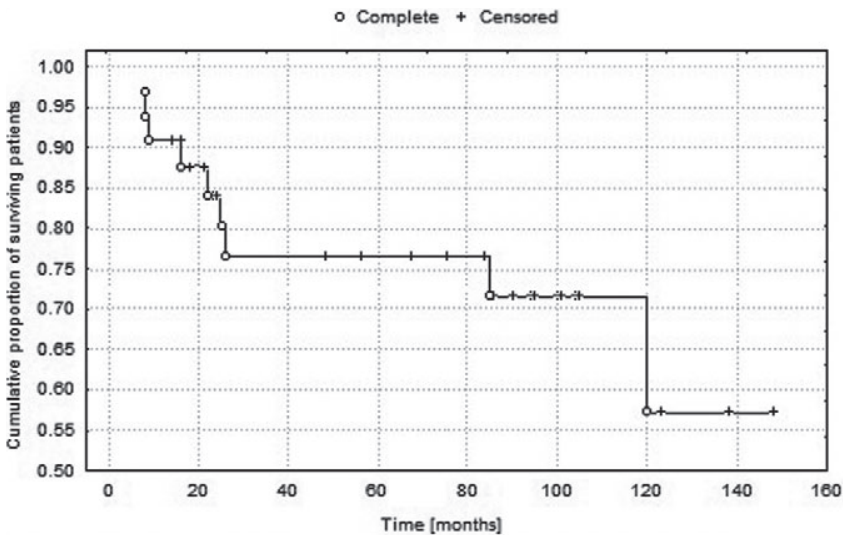

Figure 5. Kaplan-Meier plot for non-cancer-related deaths (9/33).

main requirement is the patient's agreement with repeated interventions. The concept of AT is particularly useful for patients with healed BPF and those with pleural infection without BPF. Patients with BPF can be cured according to 


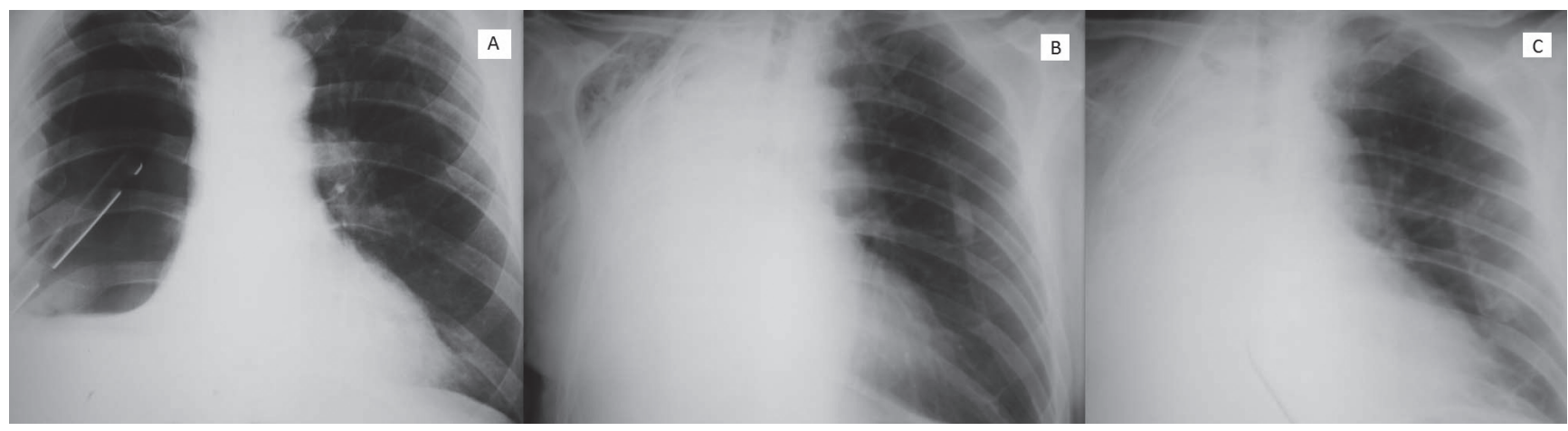

Figure 6. (A) Chest X-ray before AT. PPE condition stabilisated by drainage. (B) Chest X-ray after first intervention. Pleural cavity filled by towels without mediastinal shift. (C) Chest X-ray after final intervension. Pleural cavity filled by antibiotics solution with maintenance of neutral position of the mediastinum.

the AT approach if there is a chance to close the BPF. Bronchial stump closure insufficiency can cause povidone-iodine aspiration to the opposite bronchial tree with subsequent development of a single lung pneumonia, therefore particular attention should be given to the closure of the bronchial stump during first intervention. In three of our cases BPF was closed intraoperatively using a myoplastic procedure without any further leakage. A larger number of cases with BPF treated with use of omentoplasty technique was presented by a Swiss center $[1,7,13]$. Efficiency of previous drainage and status of

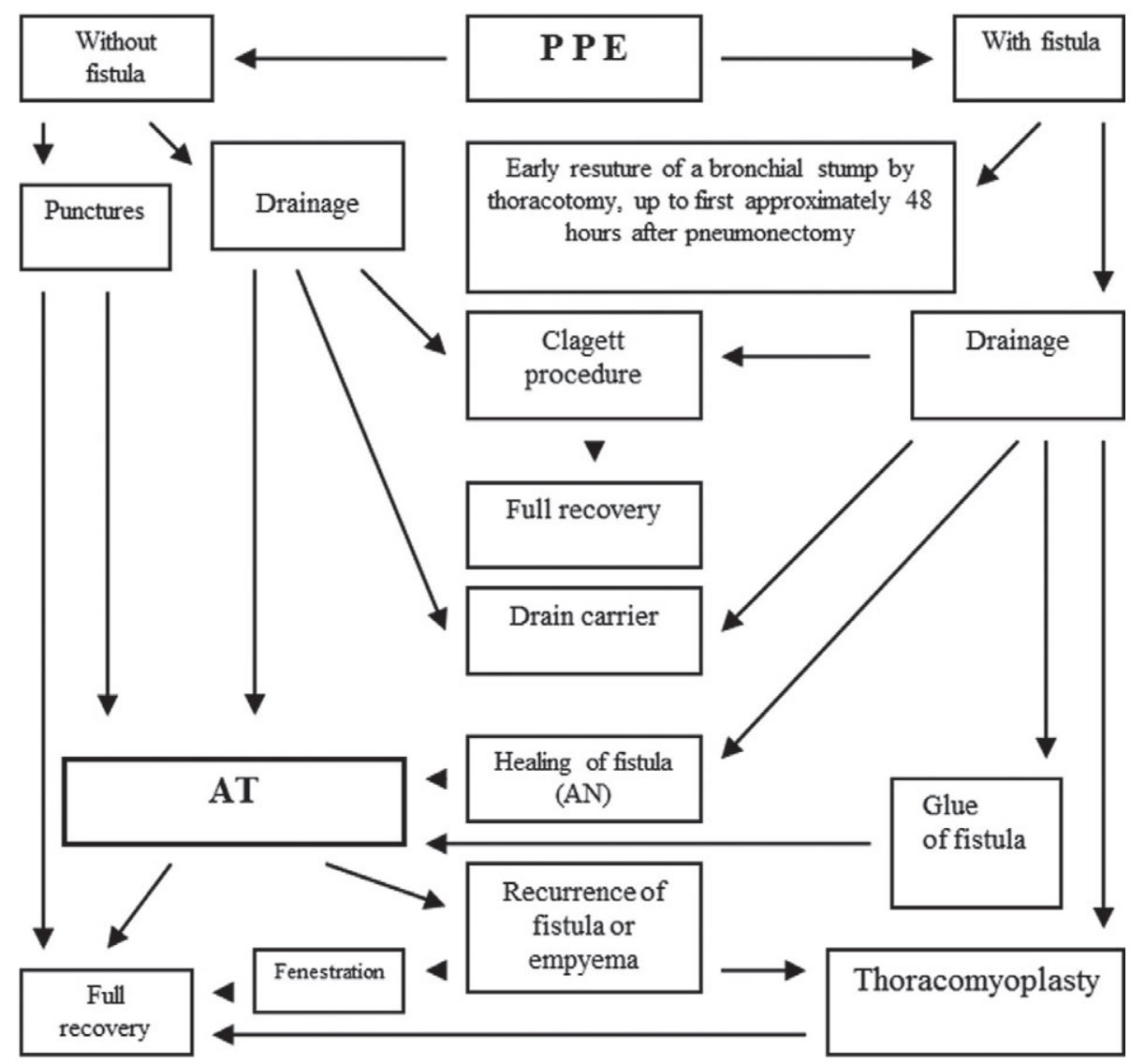

Figure 7. Algorithm of treatment of postpneumonectomy empyema (PPE) used in Thoracic Surgery Department in Szczecin. AT-Accelerated Treatment. AN-Argentum Nitrate. 
pyogenic membrane are very important factors determining final success. In six cases there was no progress in cleaning of the membrane during three interventions. Such situation requires continuation of debridement (up to eight attempts in Swiss data). A similar decision is required if an additional undetected and previously "silent" chamber of PPE is found during the second or third intervention. On the other hand, opening of all PPE chambers decreases the risk of recurrence in comparison to more conservative treatment (i.e. isolated fenestration). In our opinion, X-ray and computed tomography $[\mathrm{CT}]$ preoperative assessment must be combined with water-soluble contrast examination of the PPE chamber in the majority of cases. Obviously it must be combined with bronchoscopic control of the bronchial stump. AT does not entirely prevent PPE recurrence. There were two recurrences of BPF treated preoperatively with AN. There was no recurrence of BPF or PPE in the two patients with BPF closed by fibrin glue application; this is a promising solution for future application $[4,5,18]$. Thoracomyoplasty and open window thoracostomy with myoplasty were effective tactics for treatment of recurrent PPE; however there is still a possibility of a second AT, as previously described [10]. Every young thoracic surgeon should be aware of AT as well as of older techniques. Closure of BPF and evacuation of necrotic, fibrous, and infected tissue are the principles of PPE treatment. However, this tissue represents only the superficial layer of a thick and fibrous sack of PPE. Separation of vital structures by the remained part of the thick sack enabled local use of betadine solution (10:1) without general toxicity, renal failure or even blindness as previously described [19]. This is in contrast to peritoneal lavage for peritonitis, where saline is usually used $[1,7-$ $10,14,16]$. Position of the mediastinum stabilized by a PPE sack made it possible to fill the pleural cavity with antibiotic solution without a mediastinal shift effect (Fig.6). Evacuation of necrotic, fibrous, and infected tissue from the empyema wall is more important than the use of antibiotics for the last step of AT in the opinion of some authors [9]. This point of view is supported by the recognized lack of any bacteria in the pleural contents of $47.4 \%$ of our patients. On the other hand we didn't make repeated microbiologic tests during consecutive debridements, relying on macroscopic improvement of granular tissue. In six patients without progress during three debridements, widen microbiologic assessment to control povidone-iodine effectiveness would be probably useful. However we use povidone-iodine in our practice routinely and didn't observe clinically any influence of it on selected bacteria growth. Previous studies report reinforcement of the local leukocyte response during repeated peritoneal lavage by local application of granulocyte-macrophage colony stimulating factor [GM-CSF] [16]. Analogous use of GMCSF during pleural lavage is still theoretical, and previous attempts of intrapleural BCG vaccine immunostimulation were unsuccessful [20]. The idea of AT changed the point of view concerning large, non-collapsed, and infected cavity treatment. Elimination of such cavities was up to now the most commonly applied surgical treatment. Preservation of the pleural cavity, chest symmetry, and chest shape is one of the main goals of this method. Decreasing age of patients and improvement in NSCLC treatment outcome coexist with low level of acceptance for fenestration or thoracoplasty. There are high expectations for quality of life, activity level, and cosmetic outcome $[1,7-9,21]$. AT fulfills these needs and is a well-tolerated procedure $[7,9]$. Fourteen days is usually enough for the procedure and surveillance. The second feature for assessment of treatment efficiency is outcome in patients with malignancy. Results in patients with stage $\mathrm{N}_{0} / \mathrm{I}$ NSCLC are most promising, with a five-year survival rate exceeding $65 \%$. Stage $\mathrm{N}_{1}$ and $\mathrm{N}_{2}$ patients have five-year survivals of approximately $40 \%$ and $25 \%$, respectively [21-24]. Nineteen patients (54\%) with stage $\mathrm{T} 4$ and $\mathrm{N}_{2}$ disease survived five years. Surprisingly, $\mathrm{N}$ stage had no significant influence on survival $(p=0.90)$. In contrary, NSCLC recurrence and more than three lavages were negative prognostic factors, especially for cancer-related deaths. Furthermore, stage T4, although statistically associated with poorer survival (T2 vs T4: $\mathrm{p}=0.0496$ ) correlated with noncancer-related deaths. The results of median and cumulative survival exceeding the expected rates in the entire group are difficult to explain $[22,24]$. The phenomenon of improved survival in some patients with PPE was described 40 years ago [25]. On the other hand, there is no convincing evidence on this topic and conclusions are controversial $[2,9,20]$. Pleural empyema is mostly lethal in the terminal phase of NSCLC. The study group noted PPE in a moment of the relatively good physical condition. In the context of this result, the question of PPE influence on immunology as well as NSCLC activity still remains unanswered. In our study group there were two oncologic patients who interrupted treatment and remained drain carriers. Although they were excluded from statistical analysis, their long-term follow-up reached 86 and 122 months. PPE treatment in this aspect should be focused on quality of life after the procedure; AT adequately addresses this requirement. AT is a method that usually enables PPE treatment without thoracoplasty.

Criteria of qualification for AT are the same as for other methods used to treat PPE. Recurrence of PPE after AT can be cured by thoracomyoplasty, open window thoracostomy, or a second series of debridement. The association of AT with closure of BPF using fibrin glue can widen indications for this method (Fig.7). We conclude that AT is safe and effective. It provided cure for the vast majority of patients without thoracoplasty. The expected survival rates for each NSCLC stage are well described and defined in large series [21, 24]. PPE cancer patients tend to live longer in comparison to similar non-PPE patients regarding their oncologic stage.

\section{References}

[1] SCHNEITER D, CASSINA P, KOROM S, INCI I, AL-ABDULLATIEF $M$ at al. Accelerated treatment for early and late postpneumonectomy empyema. Ann Thorac Surg 2001; 72: 
1668-1672 http://dx.doi.org/10.1016/S0003-4975(01)030831

[2] PAIROLERO PC, ARNOLD PG, TRASTEK VF, MELAND NB, KAY PP. Postpneumonectomy empyema. The role of intrathoracic muscle transposition. J Thorac Cardiovasc Surg 1990; 99: 958-968

[3] DESCHAMPS C, PAIROLERO PC, ALLEN MS, TRASTEK VS. Management of postpneumonectomy empyema and bronchopleural fistula. Chest Surg Clin N Am 1996; 6: 519-527

[4] ORLOWSKI TM: Endoscopic closure of the broncho-pleural fistula. Pol Jour Surg 1994; 66: 449-456

[5] MARCINIAK M, KOLODZIEJ J, ORLOWSKI TM, DOMAGALA J, STANISZEWSKI A. Evaluation of therapeutic effectiveness in bronchopleural fistula. Pol Jour Surg 1994; 66: 443-448

[6] ZAHEER S, ALLEN MS, CASSIVI SD, NICHOLS FC, JOHNSON CH et al. Postpneumonectomy empyema: results after the Clagett procedure. Ann Thorac Surg 2006; 82: 279-287 http://dx.doi.org/10.1016/j.athoracsur.2006.01.052

[7] SCHNEITER D, GRODZKI T, LARDINOIS D, KESTENHOLZ P, WOJCIK J et al. Accelerated treatment of postpneumonectomy empyema: a binational long-term study. J Thorac Cardiovasc Surg 2008; 136: 179-185. http://dx.doi. org/10.1016/j.jtcvs.2008.01.036

[8] GRODZKI T, WOJCIK J, ALCHIMOWICZ J, KOCHANOWSKI L, PIEROG J et al. Time-saving procedure in the treatment of postpneumonectomy empyema. Cardiovasc Eng 2001; 6: 51-55

[9] WOJCIK J, GRODZKI T, ALCHIMOWICZ J. Pleural empyema treatment by means of Weder's method following pneumonectomy. Pol Jour Surg 2002; 74: 621-631

[10] SCHNEITER D, KESTENHOLZ P, DUTLY A, KOROM S, GIGER U et al. Prevention of recurrent empyema after pneumonectomy for chronic infection. Eur J Cardiothorac Surg 2002; 2: 644-648 http://dx.doi.org/10.1016/S1010-7940(02)00043$\underline{X}$

[11] CLAGETT OT, GERACI JE. A procedure for the management of postpneumonectomy empyema. J Thorac Cardiovasc Surg 1963; 45: 141-145

[12] ASAMURA H, NARUKE T, TSUCHIYA R, GOYA T, KONDO $\mathrm{H}$ et al. Bronchopleural fistulas associated with lung cancer operations: univariate and multivariate analysis of risk factors, management, and outcome. J Thorac Cardiovasc Surg 1992; 104: 1456-1464

[13] MARTINI G, WIDMAN J, PERKMAN R, STEGER K. Treatment of bronchopleural fistula after pneumonectomy by using an omental pedicle. Chest 1994;105:957-958 http://dx.doi. org/10.1378/chest.105.3.957

[14] GHARAGOZLOO F, TRACHIOTIS G, WOLFE A, DUBREE KJ, COC JL. Pleural space irrigation and modified Clagett procedure for the treatment of early postpneumonectomy empyema. J Thorac Cardiovasc Surg 1998; 116: 943-948 http://dx.doi.org/10.1016/S0022-5223(98)70044-3

[15] JADCZUK E. Postpneumonectomy empyema. Eur J Cardiothorac Surg 1998; 14: 123-126 http://dx.doi.org/ 10.1016/S1010-7940(98)00156-0

[16] JAKUBASZKO W, GRZEBIENIAK Z, MELEZYNSKAMATEJ M, RUDNICKI J, KIELAN W. Diffuse purulent peritonitis assisted by intraperitoneal administration of GMCSF - randomized, prospective study. Pol Jour Surg 2006; 78: 670-681

[17] BAGAN P, BOISSIER F, BERNA P, BADIA A, LE PIMPECBARTHES F et al. Postpneumonectomy empyema treated with a combination of antibiotic irrigation followed by videothoracoscopic debridement. J Thorac Cardiovasc Surg 2006; 132: 708-710 http://dx.doi.org/10.1016/j.jtcvs.2006.05.014

[18] GLOVER W, CHAVIS TV, DANIEL TM, KRON IL, SPOTNITZ WD. Fibrine glue application through a flexible fiberoptic bronchoscope. Closure of bronchopleural fistulas. J Thorac Cardiovasc Surg 1987; 93: 470-472

[19] WAGENFELD L, ZEITZ O, RICHARD G. Visual loss after povidone-iodine pleurodesis. N Engl J Med 2007; 357: 1264-1265 http://dx.doi.org/10.1056/NEJMc070128

[20] THE LUDWIG LUNG CANCER STUDY GROUP (LLCSG). Immunostimulation with intra-pleural BCG as adjuvant therapy in resected non-small cell lung cancer. Cancer 1986; 58:2411-2416 http://dx.doi.org/10.1002/1097-0142(1986120 1)58:11<2411::AID-CNCR2820581110>3.0.CO;2-C

[21] JASSEM J, SKOKOWSKI J, DZIADZIUSZKO R, JASSEM E, SZYMANOWSKA A et al. Results of surgical treatment of non- small cell lung cancer: validation of the new postoperative pathologic TNM classification. J Thorac Cardiovasc Surg 2000; 119: 1141-1146 http://dx.doi.org/10.1067/ mtc. 2000.105825

[22] MOUNTAIN CF, DRESLER CM. Regional lymph node classification for lung cancer staging. Chest 1997; 111: 1718-1723 http://dx.doi.org/10.1378/chest.111.6.1718

[23] GRODZKI T, WALECKA A, FABIAN W, DANIEL B, WITKIEWICZ I et al. Program of early detection of pulmonary neoplasm by the computed tomography - preliminary experience. Pneumonol Alergol Pol 2009; 77: 521-527

[24] NARUKE T, GOYA T, TSUCHIYA R, SUEMASU K. Prognosis and survival in resected lung carcinoma based on the new international staging system. J Thorac Cardiovasc Surg 1988; 96: $440-447$

[25] RUCKDESCHEL JC, CODISH SD, STRANAHAM A, MCKNEALLY MF. Postoperative empyema improves survival in lung cancer: documentation and analysis of a natural experiment. N Eng J Med 1972; 287: 1013-1017 http://dx.doi. org/10.1056/NEJM197211162872004 